\title{
Strategic actors and their scenarios in the extraction of phosphates from the Mantaro Valley
}

\author{
Israel Mallma ${ }^{1} \oplus$, Lita Salazar ${ }^{2} \bullet$ \\ ${ }^{1}$ Doctor in safety and control in mining, Master in mining management, faculty of mining \\ engineering, graduate school of the National University of the Center From Peru; \\ israel_minner@hotmail.com \\ 2 Doctor in Educational Sciences, Master in Educational Management, Faculty of Education, \\ graduate school of the National University of the Center of Peru; litapierina@ hotmail.com
}

\begin{abstract}
A prospective analysis and the alternative regarding the stakeholders, the objectives and the policies using the Lipsor methodology (Mactor, Micmac, Multipol and Smic-Prob-Expert, referring to the extraction of phosphates from the Mantaro Valley (with Estimated reserves of up to 376.2 million tons), it results that the mining extraction project has no influence, with the interests of the community.In the convergence plane we can observe the phosphate project are within the field of Power variables. The applied policies have an average of 9.5, while $\mathrm{q}$ the other actions of the actors have an average of 13.3 to 15.7. Regarding the proposed scenarios in five categories of very bad very good, it is detailed that in the aspect economic and labor has an average of 21.2, the one with the greatest implication, followed by the aspect of respect for rights 20 the social and environmental issue has a score of 19.9, the dialogue issue is 19. In short, the proximity plan shows us that the policies used regarding the issue of generating employment and economic growth (Empresa Mantaro Perú SAC), continue to be the strategic variables in the first instance, but that they are far from the social actors (rural communities of Aco, Vico, Cruz Pampa and others) and environmental actors (Junín environmental dialogue table) and the Ombudsman's Office (rights) that are currently closer together. The actor from the Archbishop of Huancayo referred to communication is one of the driving variables of power.
\end{abstract}

Keywords: Prospective analysis, strategic actors, scenarios, objectives, policies, phosphate extraction, mining project, peasant communities. 


\section{INTRODUCTION}

Phosphates are minerals with a high content of phosphorus, a fundamental element for living organisms. Phosphates are found in nature concentrated in "phosphate rocks", from which they can be extracted for industrial use. Phosphate rocks is the trade name for rocks that contain one or more phosphate minerals, generally from the apatite group, the base of which is calcium phosphate. These rocks can be used directly as fertilizers, or as a source of phosphates and phosphorus, for which they are subjected to concentration and purification treatments, finally being sold as commercial products.

Phosphorus is one of the vital elements for agriculture and for life in general since it is part of all food chains, passing from one organism to another. Phosphorus is involved in almost all chemical reactions, whether in mineral compounds or in organic combinations (lecithin, phytins, proteins).

(Iván Martínez, 2013) The most important potential mineral source of phosphorus in the soil is apatite, which comes from the Greek word apatao, which means to be wrong, because it was confused with some gems

Apatite has at least three forms depending on the anion present: fluorapatite, chloroapatite and hydroxyapatite $\mathrm{Ca} 5$ (F, Cl, OH) (PO4) 3. Normally apatite is found concentrated in deposits called phosphorite or phosphate rock. (Department of Geology, University of Chile, 1998)

(Cabezas Juvenal, 2020) After half a century after phosphates were discovered, in August 2010 the export of phosphates from Bayóvar to Brazil began through the company Miski Mayo SRL, subsidiary of the Brazilian company Vale do Río Doce. For the exploitation and export of phosphates, Vale developed the Bayóvar Project, which has a nonmetallic mining approach that contemplated the exploitation of a surface deposit of phosphate rock, its processing to produce concentrates and its shipment for export.

(Cabezas Juvenal, 2020) Likewise, Bayóvar phosphates can serve as raw material for the production of phosphoric acid, which serves to manufacture a very important family of fertilizers worldwide that includes monoammonium phosphate (MAP), diammonium phosphate (DAP), triple superphosphate (TSP) and simple superphosphate
(SSP). These fertilizers, together with urea, ammonium nitrate, ammonium sulfate and potassium chloride, constitute the great family of NPK fertilizers, highly required as fertilizers in agricultural fields, because they contain nitrogen, phosphorus and potassium.

Lines below are shown Table 1 Calculation of Resources of the measured minerals indicated and inferred from a satellite image with respect to the phosphate deposits in the Mantaro Valley.

As is known, the management of information in all aspects must be well disseminated, including all the influences that its production would bring to the region aspects such as social, environmental, economic and business. As Junín has one of the most reserves found, we have phosphate for the next 200 years and this quality of this mineral found is superior to that of other reserves in the country.

A simple explanation of the application of phosphate deposits is to obtain fertilizers, but also a transformation of the phosphates obtained from phosphate rock leads to the obtaining of numerous products such as plasticizers, detergent fillers, water softeners, insecticides, additives for petroleum and metallurgical products, etc. (Campodónico, H, 2015) All these applications lead to propose that a part of said phosphates remain in the country for their transformation and to contribute to the industrialization of Peru.

\section{MATERIALS AND METHODS}

In this aspect, we will detail the study area, the resources and the current context in the environmental, social, business and economic issue of the communities.

The analysis offered is of a sociodemographic nature, delimited by the space covered by the Mantaro Exploration project with the objectives of the actors in economic, environmental, regulatory, dialogue and respect for citizen rights. This analysis will be done with the software of the Research Laboratory in Prospective, Strategy and Organization (Lipsor).

\subsection{Study area}

The Mantaro Project is politically located in the Aco district, belonging to the province of Concepción, within the jurisdiction of the department of Junín; within the superficial lands 
owned by the Rural Communities of Aco, San Antonio de Quicha Chico and Quicha. Likewise, it is located within the mining concessions: Philip and Quicha Chico. Access to the Project area from Lima is through the fully asphalted Central Highway until Km. 295, it deviated to Aco about $6 \mathrm{Km}$. Of affirmed road where the Project begins.

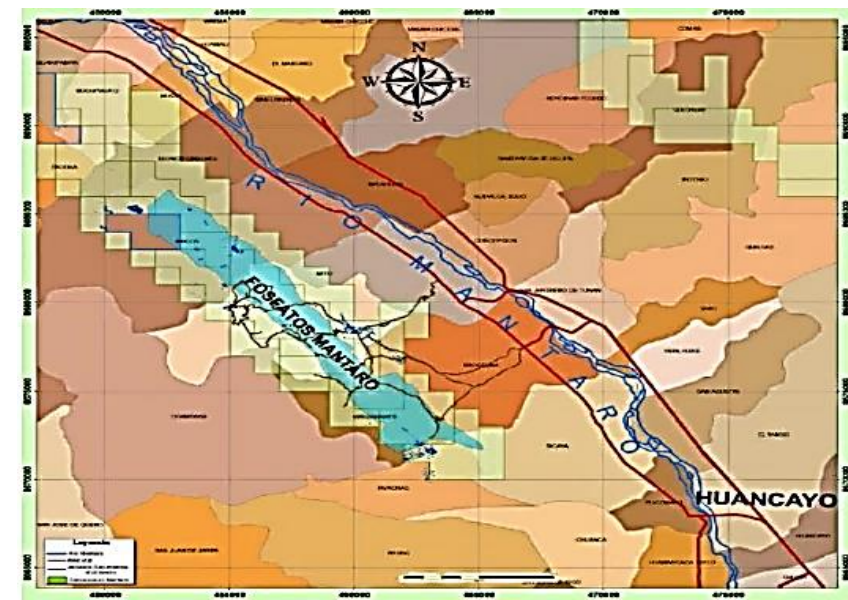

Figure 1 Geographical location of phosphate deposits Phosphate

\section{1. resources}

The company has delineated in Mantaro 39.5 Mt in measured and indicated resources@10\% P2O5 (phosphate rock), in addition to 1,500 Mt in inferred resources @ 10-12\% P2O5, and a geological potential greater than 2,000 Mt. Thus, a deposit unique in the world due to its age (190Ma -200Ma), for its large tonnage and for its mineralogical characteristics is on the way to start commercial production - it does not have traces of base metals No rare earths, only phosphate rock and minute amounts of silver.

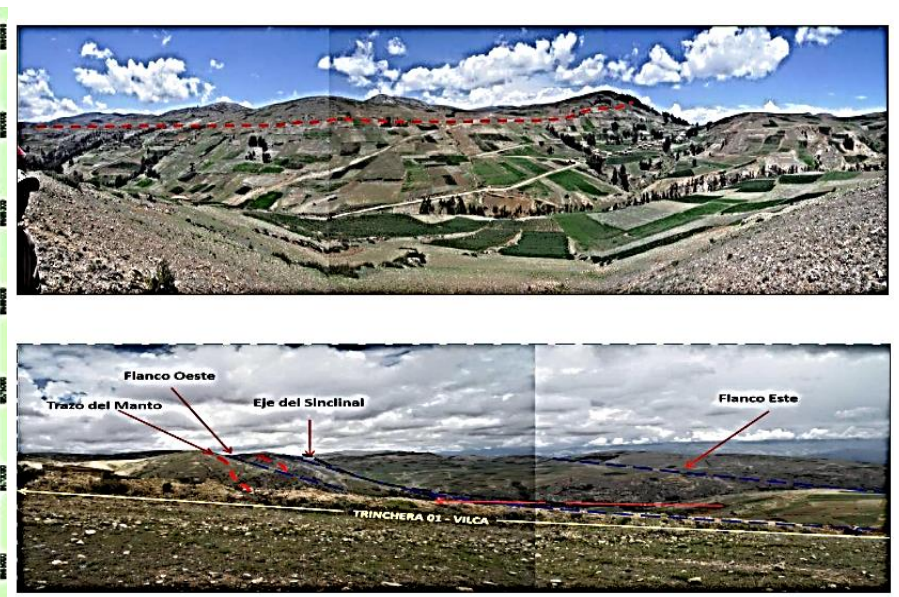

With respect to the measured-indicated and inferred mineral resources they are:

Table 1 Calculation of Resources of the indicated and inferred measured minerals

\begin{tabular}{|c|c|c|}
\hline Resources & Tons & P2O5\% \\
\hline Measured & $5,548,000$ & 10.8 \\
Indicated & $33,975,000$ & 9.9 \\
Sub Total & $\mathbf{3 9 , 5 2 3 , 0 0 0}$ & $\mathbf{1 0}$ \\
Inferred & $1,500,000,000$ & $10-12$ \\
\hline
\end{tabular}

Table 2. Coding of the 37 concessions that include 12,800 hectares the detail of concessions according to the registration number in Ingemmet

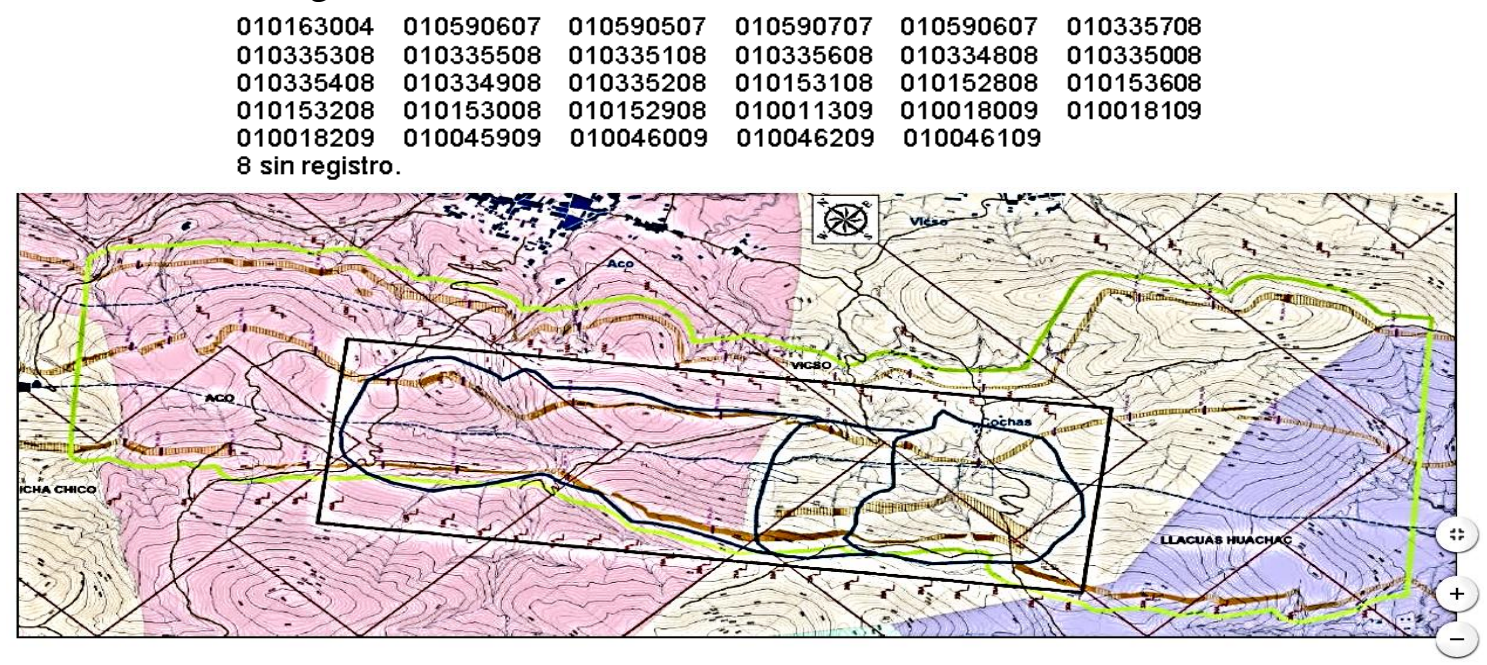

Figure 2 Location of the phosphate concessions in the district of Aco 


\subsection{Environmental aspect}

\section{The soils}

They are relatively deep, clayey, of acid recreation, reddish to brown tones and that assimilate the Phaezems edaphogenic group. Likewise, where calcareous lithological materials predominate, Kastonozems may appear, generally with reddish tones. In very steep areas, thin soils appear giving way to Lithosols and some forms of Rendzinas, as well as transitional groups belonging to Cambisols (dystric and eutric).

\section{Micro- hydrographic}

basins In the area of interest there are two hydrographic micro-basins which are currently in the absence of water: the Quebrada Machiqui microbasin and the Vicso river micro-basin.

\section{Vegetation}

The naturalvegetation climaxpractically does not exist and is reduced to small remnants or homogeneous residual forests, such as "Chachacomo" (Escallonia sp), "ulcumano", "romerillo" or "intimpa" (Podocarpus sp) or small heterogeneous forests made up of species of the genera Gynoxis, Polylepis, Berberis, Eugenia, Senecio, Podocarpus, Baccharis, Oreoponax, Solaum, etc.

\section{Fauna}

Represented by the cattle and sheep that the inhabitants of the peasant communities raise as sustenance (in the case of cows and sheep) and means of transport (horses). Wild birds present in the project: turtle dove (Metriopelia melanoptera), partridge Serrana or Pisacca (Notoprocta ornata), Thrush or Chihuaco (Turdus chiguanco), Yellowwinged Trile or Chencco (Agelanus thilius), which lives in the grasslands, similar to thrush or blackbird, Wild mammals: skunk (Conepatus chinga), vizcacha ( Lagidium peruanum), wildcat (Oncifelis colocolo).

\section{$>$ Environmental Impacts}

The exploration project carried out by the Mantaro company would cause an impact on the soils at the local level due to the modification to the topography and the landscape, in the water resources there is a recommendation not to be located less than $50 \mathrm{~m}$ from the water courses sporadic or permanent water, in terms of air it is mentioned that combustion products (NOx, SOx and particulates) are negligible due to the volume that will be consumed during exploration activities, the physiographic of the area and the winds present in the area, the which do not result in an accumulation of air pollution.

\subsection{Social aspect}

The Social Base Line offers a general analysis of the Peasant Communities of Quicha and San Antonio de Quicha Chico, (these first two were worked on in November 2008); while the Rural Communities of Aco (it was worked in February 2009), located in the district of Aco, province of Concepción, department of Junín.

\section{$>$ Social conflicts}

(Candiotti Juan, 2016) The mining company Mantaro Perú SAC, between 2008-2013 carried out mining explorations (on the farms of the peasant community), the basis for studies of pre-feasibility, feasibility, possible construction and operation of the deposit of phosphates; In this context, conflicts arose between the community members of the Aco Campesino Community, residents of the Aco district and the mining company, later the conflict reached its stage of crisis, a stage in which the population violently rejects the mining activity of Mantaro Perú SAC reason for which the company stops exploring.

To analyze whether the exploitation of phosphates is feasible, then the objectives are dissimilar because if the mineral is exploited, the community member perceives that he will lose his lands, from which he obtains the sustenance for his family. Values, truth, respect are highly valued in the peasant community, so when one party lies (according to communal leaders interviewed, the mining company lied, not respect) they feel violated and therefore the community members take a defensive position.

It is a fact that between the peasant community and the Mantaro Perú SAC mining company there is a high asymmetry, and the State, which is the party called upon to balance the balance, had a poor and late participation.

Among the evidences of the social conflict between the mining company and the districts that are linked to it, it can be detailed: the complaint of mistreatment and hostility against authorities and residents of the district of aco before the court of the peace of first nomination February 23, 2011 and the pints No of rejection of the Mantaro SAC mining company in the Aco district and the rejection and protest of the residents of the districts linked to the phosphate 


\subsection{Business aspect}

depositThe deposits of the Mantaro valley were discovered in 1960 by Minera Mantaro SA, while it scanned for vanadium. It went through several hands since then, until in 2007 it was acquired by Sprott Resources, which partnered with Stonegate Agricom in 2008, forming the Mantaro Perú SAC joint venture. (Mantaro Peru SAC, 2013)

\section{$>$ Exploration workexploration}

Theprogram to be executed in this Environmental Impact Statement of the Mantaro Project includes the execution of sixteen (16) drill holes (of which two (02) correspond to diamond drilling and the 14 remaining reverse air distributed) in seven (07) drilling rigs and twelve (12) trenches, whose area delimited work for (01) polygon ten (10) vertices amounts to $340 \mathrm{Ha}$

the diamnatinas perforations tubieron an angle of $-45^{\circ}$ and $-90^{\circ}$, and the trenches $2 \mathrm{~m}$. deep and a range of 50 to 90 meters in length.

Figure 3 shows the exploration program to be executed in this Environmental Impact Statement of the Mantaro Project, which includes the execution of sixteen (16) drill holes (of which two (02) correspond to diamond drilling and the remaining 14 to reverse air distributed) in seven (07) drilling platforms and twelve (12) trenches, whose work area delimited by a (01) polygon of ten (10) vertices amounts to $340 \mathrm{Ha}$.

The diamond drilling had an angle of $-45^{\circ}$ and $90^{\circ}$, and the trenches $2 \mathrm{~m}$. deep and a range of 50 to 90 meters in length.

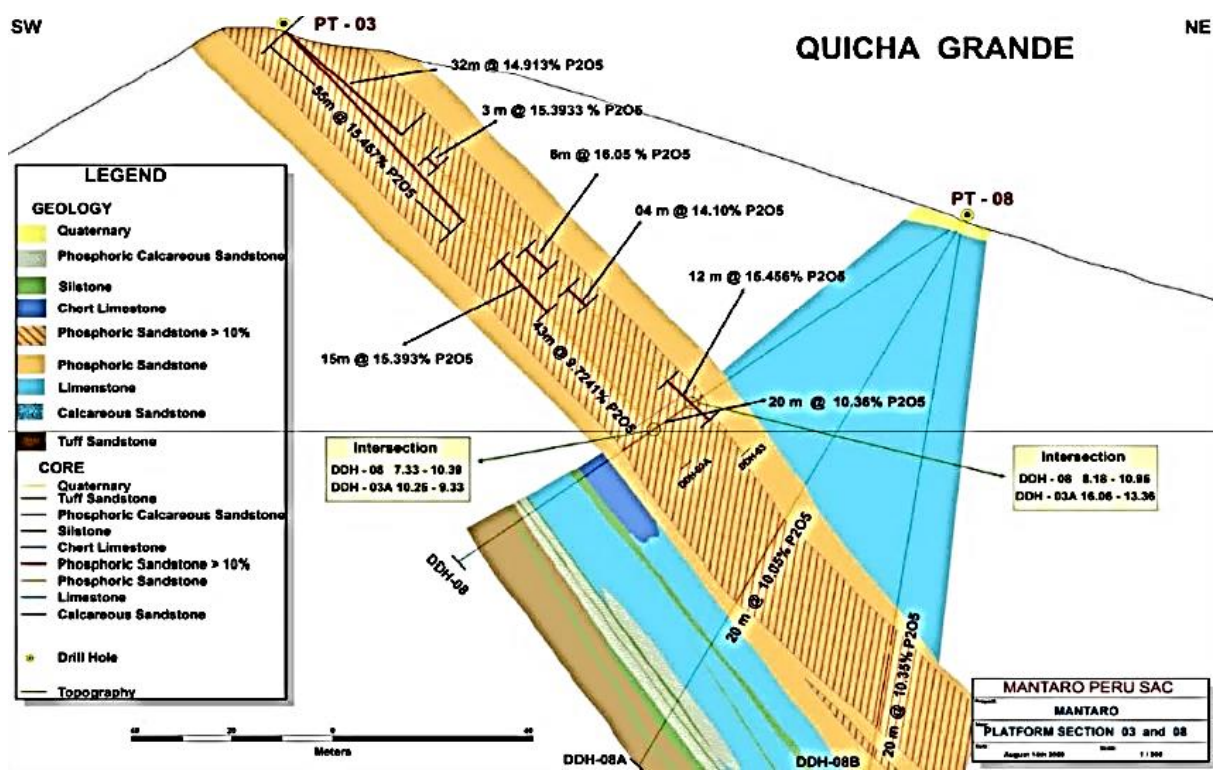

Figure 3 Detail of the drilling in the Aco fields

\subsection{Regulatory aspect}

Organic Law for the sustainable use of natural resources Law No. 26821, mentioned in article 23.The concession The concession, approved by special laws, grants the concessionaire the right for the sustainable use of the natural resource granted, under the conditions and with the limitations established by the respective title. In article 18 it mentions: Peasant and native communities have preference in the sustainable use of the natural resources of their lands, duly titled, unless expressly reserved by the State or exclusive or exclusive rights of third parties.

Law No. 29785. Law of the right to prior consultation with indigenous or native peoples, recognized in Convention 169 of the International Labor Organization (ILO) in Article 2. Right to consultation. - It is the right of indigenous or native peoples to be previously consulted on legislative or administrative measures that directly affect their collective rights, on their physical existence, cultural identity, quality of life or development

\subsection{Economy and impact on communities $>$ The community de Aco}

According to (Inei, 2007) the district of Aco has 894 private homes and 1951 inhabitants. Handicraft activities such as ceramics represent the local and domestic economy, while providing them with a very useful element of exchange. As this is 
combined with the agricultural activity that takes place in the community, the farms they have are insufficient and the random agricultural production of the cultivation of potatoes, corn and barley. due to weather conditions. Aco is characterized by being a town of eminent artisans, and also by dedication to working in the fields. Aco, has three educational centers, two at primary level and one at secondary level, it has sanitation, water, partially developed sewage service, telephones, Internet, etc. On Fridays they hold fairs in which agricultural products and pottery products such as pots, vases, porongos, lamps, toys and baked clay ornaments are sold.

\section{$>$ The community of Vicso}

According to (Inei, 2007) the district of Visco has 273 private homes and 598 inhabitants. They are producers of more than 50 varieties of potatoes, raising sheep, pigs and cattle, as well as small animals such as guinea pig and poultry. Among its most widely sown products are wheat, barley, linseed, potatoes, beans, peas and corn, agriculture is traditionally practiced with yunta. On the other hand, tractors are also used, their fields being highly productive, for which the production is not only for self-consumption, but is also commercialized in the local market and in the capital of the country.

\section{$>$ Community of Cruz Pampa}

According to (Inei, 2007) the district of Cruz Pampa has 45 private homes and 211 inhabitants. Agriculture is the essential activity of the inhabitants of Cruz Pampa; based on family work; $100 \%$ of the PEA is dedicated to this activity. Its main crops are: potatoes, barley and oats. However, they also sow goose, mashua, broad beans and olluco on a smaller scale. Sowing is mostly done using traditional tools, such as the plow, the pick and the lampa. Few of those who bear tractors for planting or breaking their land. None of the arable land has channeled irrigation systems, so that $100 \%$ of the arable land is rainfed, which is why sowing is carried out during the months of September, October and November, the rainy months.

\section{$>$ Social impacts on communities}

The social impacts are related to:

1. Cultural confrontation between workers who are not from the areas and native inhabitants.

2. Fear of the population for the negative social and / or environmental impacts that the Project may cause.
3. Overestimated expectations of benefit of the population in relation to the

4. project itself (creation of false expectations regarding mining activities).

5. Possible run over of cattle of the shepherds by the passage of the vehicles.

\subsection{Data analysis}

The computer instruments for data processing are the Micmac, Mactor, Multipol Smic-ProbExpert type tools that allow you to save time and synthesize all the information in one place for easier handling. (Godet Michel, 2007)

\section{RESULTS}

\subsection{Analysis of the actors and their objectives}

It is considered 5 actors present in the development of explorations of the mining project. Respect for the actors and objectives within the project are detailed below:

\section{$>$ Strategic actors}

1. Empresa Mantaro Perú SAC

2. Peasant communities of Aco, Vico, Cruz Pampa and others

3. Archbishopric of Huancayo

4. Roundtable for environmental dialogue Junín

5. Ombudsman's Office

\section{$>$ Objectives of the actors}

1. Implement and execute the phosphate project to ensure the economic sustainability of the company

2. Continue with its agricultural and livestock activities without the presence of the mining company

3. That the rights of peasant communities are respected

4. Generate spaces for dialogue

5. Respect for the rights of citizens

\section{$>$ Strategic policies}

1. Generate employment and economic growth

2. Community interests (environmental risk, loss of cultivation areas, community fragmentation)

3. Comprehensive development, conservation of resources, respect of agreements 
4. Horizontal dialogue, respect for the rights of both parties

5. Avoid the violation of the fundamental rights of people
To said analysis we support With the Mactor software, which makes an analysis of influence and dependence between the actors and objectives of a project, the data entry is shown below in Table 3.

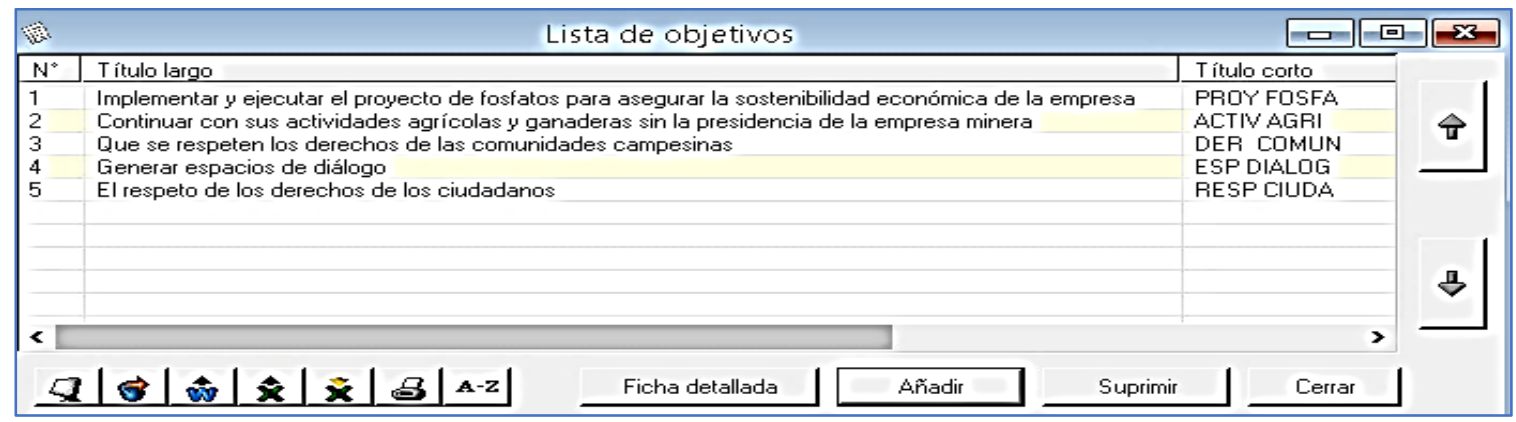

Figure 4 List of objectives according to the actors linked in the project of Mantaro Valley phosphate deposits

From the graph of direct influence of actors and objectives

Said procedure of direct and indirect influence, between the actors and objectives of the mining project, can be seen below lines which have been processed in the Mactor program. Regarding the graph of direct influence, we can rescue two aspects: the mining projects do not have influence, with the interests of the community, and they did not work with the influence towards the other interests of the actors, whether primary or secondary, which is why which is noted its paralysis that in sum is not the inadequate management of the mining company Mantaro SAC.

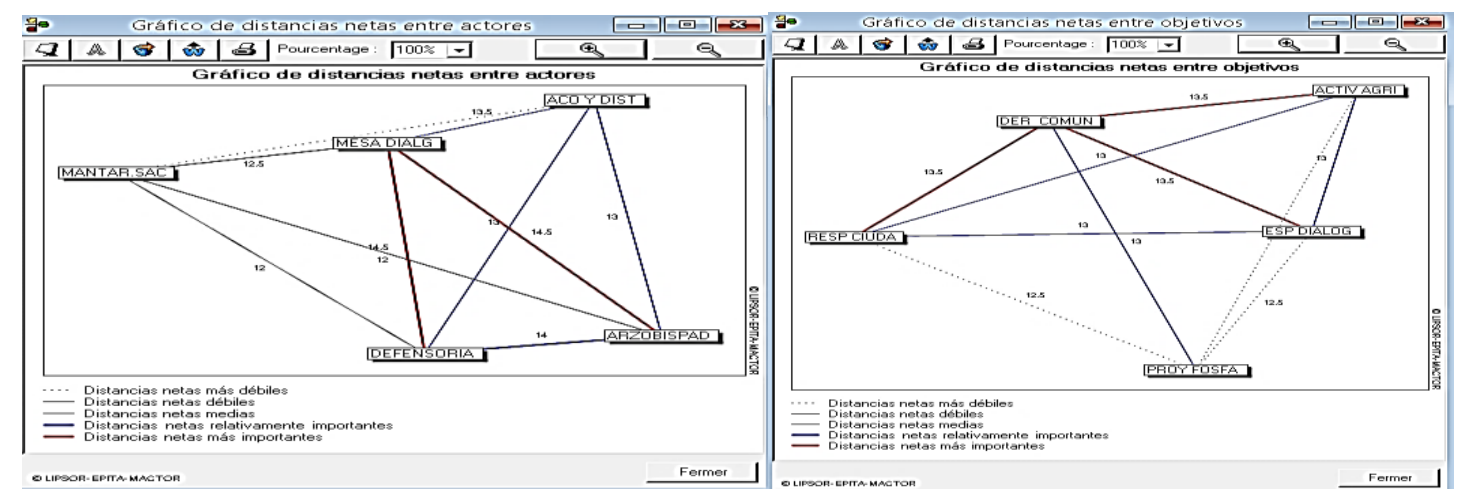

Figure 5 Influence between actors and between objectives of the Mantaro Valley phosphate deposits project

Within the analysis of the objectives, it can be mentioned that the phosphate project and agricultural activities with respect to the districts linked to this deposit have no direct relationship , as shown by the dotted lines in the graph of net distances between objectives (weakest net distances as shown in the figure)
With respect to the convergence plane we can observe the project of phosphates are within the field of power motor variables, and the agricultural activities concerning the district of aco is in the quadrant of strategic motor variables, this indicates that the strategies worked by the mining company should be focused in this sense and directed to actions that lead to said objectives. 


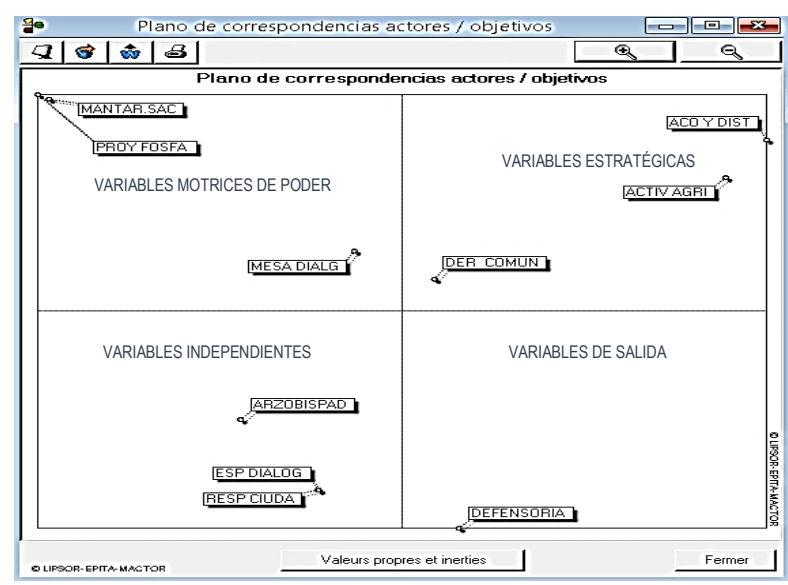

Figure 6 Map of correspondence between actors and objectives of phosphate deposits in the Mantaro Valley

With respect to the evaluation regarding the applied policies, we can see that the project carried out by the mining company has an average of 9.6 which is shown in the table lines Below, this shows that what is mentioned regarding the influence between the objectives with respect to the mining company and the other actors is very low. The evaluation of actions based on the policies applied in said project by the mining company shows that the objectives of continuing with its agricultural and livestock activities and in the presence of the mining company has an average of 13.3 which is related to the other objectives. of the different actors that were mentioned above in a Range of 14.8 to 15.7 . The detail is shown below

Table 3 Evaluation of the actions based on the objectives of the phosphate deposits project of the Mantaro Valley

\begin{tabular}{|c|c|c|c|c|c|c|c|}
\hline 专 & \multicolumn{6}{|c|}{ Evaluación de las acciones en función de las políticas } & $=-\mathrm{x}_{\mathrm{x}}$ \\
\hline 9 & พิ & $\tilde{\mathbf{x}} \mathbf{g}$ & & & & 9 & $\Theta$ \\
\hline & Acciones:Polticas & 1: EMPL ECON & 2 : SOCIALL & 3: AMBIENTAL & $4:$ COMUNIIC & 5: DERECHOS & 6: Moy. \\
\hline 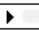 & 1:PROY FOSFA & 11.2 & 9.2 & 8.3 & 9.2 & 10.2 & 9.6 \\
\hline & $2:$ ACT AGRAR & 12.8 & 13.5 & 14 & 13 & 13 & 13.3 \\
\hline & $3:$ DER COMUINII & 14.1 & 15 & 15.4 & 15.1 & 14.6 & 14.8 \\
\hline & 4 : D|ALLOGO & 14.6 & 15.8 & 16.1 & 16.1 & 15.4 & 15.6 \\
\hline & $5:$ DER CIUDAD & 15.7 & 15.6 & 15.6 & 16 & 15.6 & 15.7 \\
\hline 1 & & & & & & & , \\
\hline
\end{tabular}

This aspect can also be represented by a profile policies applied in the Mantaro Valley phosphate plan in which it shows that the phosphate project has project.

objectives with low results with respect to the

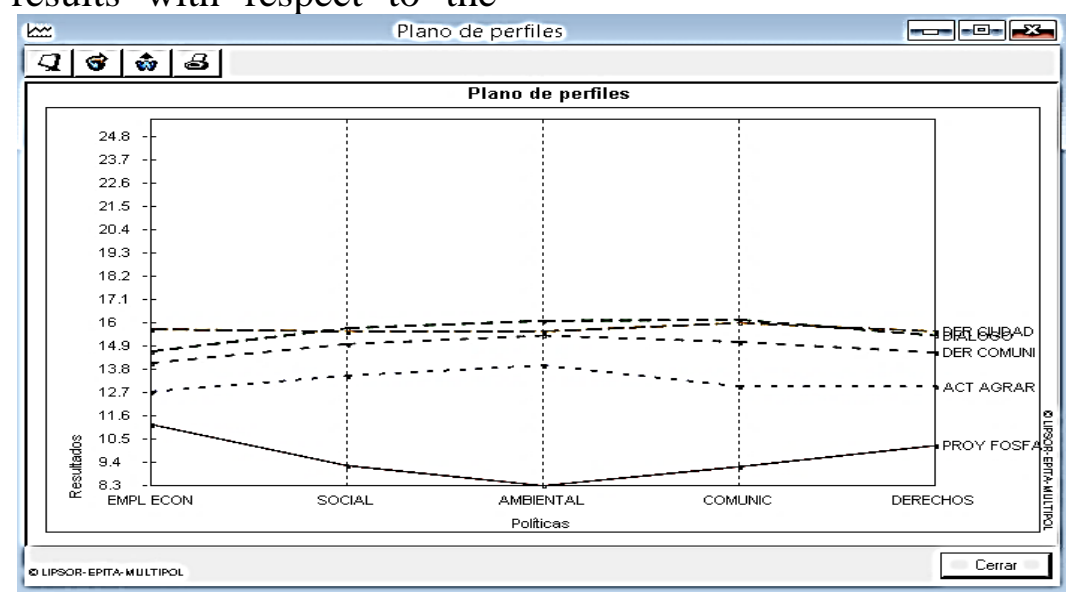

Figure 7 Plan of the policy profile based on the objectives in the phosphate deposits of the Mantaro Valley 


\subsection{Proposed scenario}

This analysis was carried out with the Múltipol program (compare different actions or solutions to a problem based on criteria and strategic objectives) belonging to LIPSOR (Laboratory of Research in Prospective, Strategy and Organization) which helps with the reading of the profiles of the policies based on the objectives and the policies based on the possible scenarios. For this case, we will carry out an analysis of the policies based on the possible scenarios that go from very bad to very good.

Regarding the scenarios proposed in five categories of very bad very good, it is detailed that in the economic and labor aspect it has an average of 21.2 , followed by the aspect of respect for rights, 20 the social and environmental issue has a score of 19.9 , the topic of dialogue is 19. All these evaluations are evaluations of the policies based on the scenarios from very bad to very good.

Table 4 Scenarios projected considering the inclusion of economic, social, environmental, legal and dialogue in the phosphate deposits in the Valley of the Mantaro

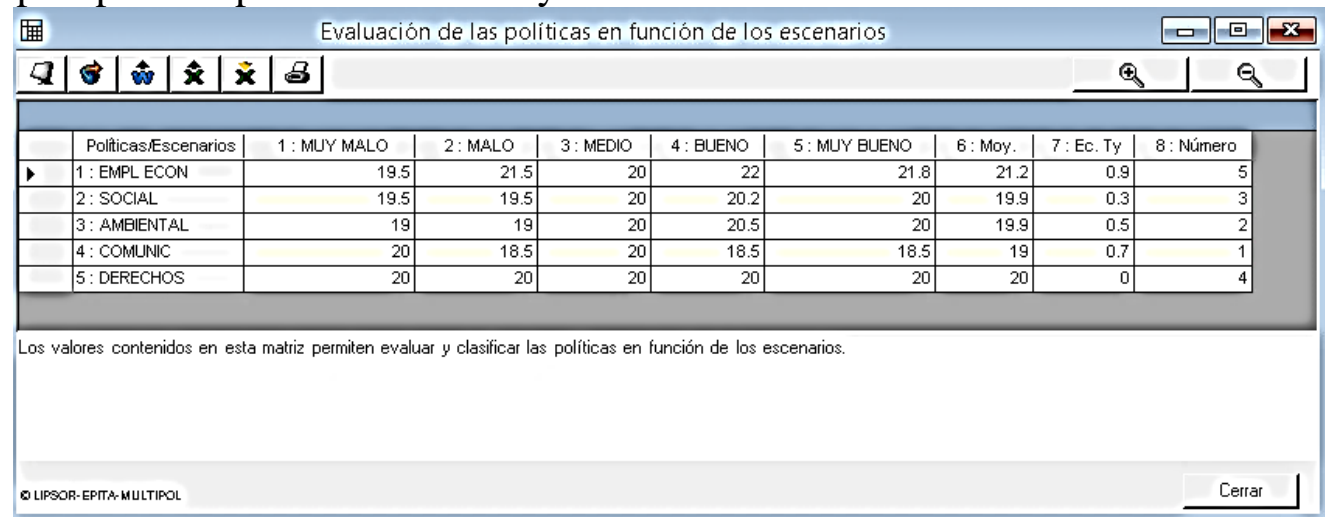

In short, the plane of plane proximity indicates that the policies employed concerning the issue of generating employment and economic growth (Empresa Mantaro Perú SAC), continue to be the strategic variables in the first instance, but they are far from social actors (rural communities of Aco, Vico, Cruz Pampa and others) and environmental (Junín environmental dialogue table) and Defensoría of the people (rights) that are most closely related today.

Regarding the actors of the Archbishopric of Huancayo, which refers to communication, it is within the driving variables of power that is also not far from the means of the policy evaluations based on the scenarios.

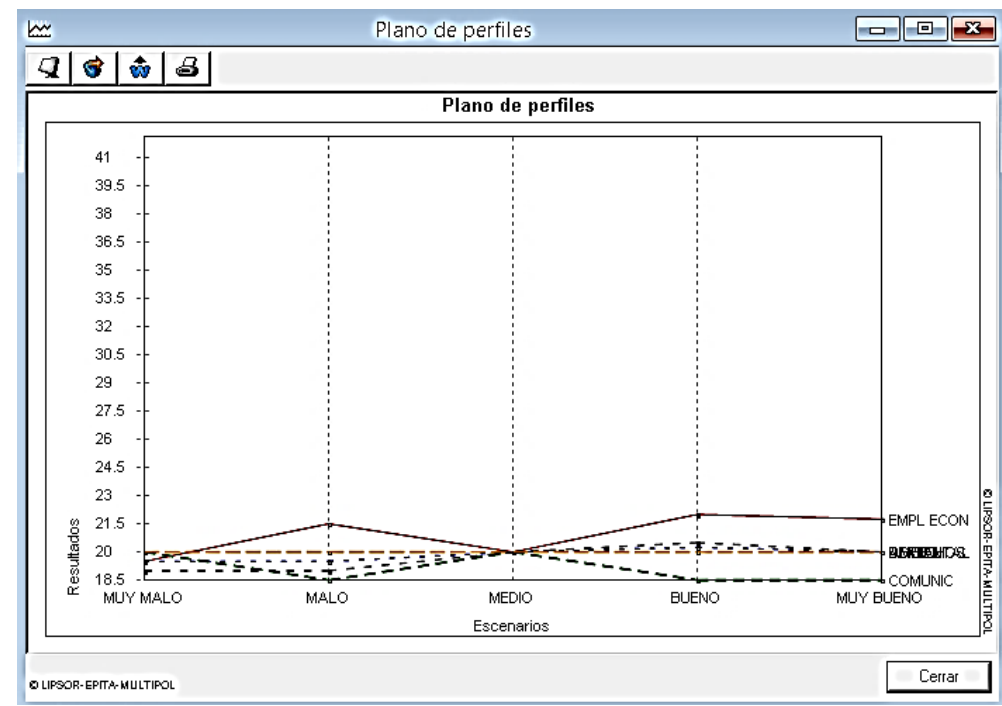

Figure 8 Map of proximity of policies and projected scenarios considering the inclusion of economic, social, environmental, legal and dialoguethe Mantaro Valley 
policies in the phosphate deposits ofWe can detail that the policies applied in the phosphate deposit of the Valle del Mantaro, to have very good scenarios that include all the Goals and their actors, should consider: that the actions applied in said goals have almost the same influence on their different actors and avoid biases of only applying economic and employment strategies, as stated At present, the social and environmental issue as well as the legal, communication and dialogue issue are important for the development of the districts and the province of Concepción in the Junín region.

\section{CONCLUSIONS}

From the graph of direct influence of actors and objectives, we detail that the mining projects have no influence, with the interests of the community, and the influence towards the other interests of the actors, whether primary or secondary, was not worked on. by which its paralysis is noted, which in sum is not the inadequate management of the mining company Mantaro SAC.

With regard to the convergence plane, we can observe the phosphate project is within the field of power motor variables, and the agricultural activities concerning the district of ACO is in the quadrant of strategic motor variables, they are in different quadrants.

The policies based on the objectives of the phosphate project have low results, it is detailed that the project applies inadequate policies in the economic, environmental, regulatory, dialogue and respect of rights, as shown in Table 3, The actions of the policy in these aspects have an average of 9.5 while the other actions of the actors have an average of 13.3 to 15.7

Regarding the proposed scenarios in five categories of very bad very good, it is detailed that in the economic aspect and The labor market has an average of 21.2 , followed by the respect for rights aspect, 20 the social and environmental issue has a score of 19.9, the dialogue issue is 19 .

In sum, the proximity plan shows us that the The policies used regarding the issue of generating employment and economic growth (Empresa Mantaro Perú SAC), continue to be the strategic variables in the first instance, but they are far from the social actors (Communities rural women of Aco, Vico, Cruz Pampa and others) and environmental
(Junín Environmental Dialogue Table) and Ombudsman's Office (rights) that are currently closer together.

Regarding the actors of the Archbishopric of Huancayo, which refers to communication, it is within the driving variables of power

\section{RECOMMENDATIONS}

The phosphate exploitation project of the Mantaro Valley should focus on strategies and policies that go hand in hand with the actors such as the rural communities of Aco, Vico, Cruz Pampa and others), this also involves involving environmental actors (Junín Environmental Dialogue Table) and the Ombudsman's Office (rights, which allows the identification of a legitimate agenda, capable of collecting the true interests in a mining project), so that the most appropriate and sustainable decisions can be made from them.

\section{Author contributions}

This present explains that the policies applied in the exploitation of the phosphate deposit of the Mantaro Valley are not adequate, this because the actors do not make adequate decisions, the important factors that must be included are the economic and labor issue, which must be be aligned with environmental and social policies.

\section{Conflict of interest}

The authors declare that this article was carried out in the absence of commercial or financial relationships that could be interpreted as a possible conflict of interest.

\section{Expressions of gratitude}

The authors wish to thank the reviewers for their valuable comments, aimed at improving the communication, effectiveness, and overall quality of this manuscript. 


\section{References}

Cabezas Juvenal. (July 27, 2020). Exploitation of phosphate deposits in BayóvaR. Obtained from www.urp.edu.pe: http://revistas.urp.edu.pe/index.php/Perfiles _Ingenieria/article/download/408/404/

Campodónico, H. (2015). Lima: The republic.

Candiotti Juan. (2016). Causes of the socioenvironmental conflict between the rural community of aco - concepción and the mining company mantaro perú sac 20082013. Huancayo: Peruvian University the Andes.

Ombudsman.

http://www.defensoria.gob.pe/temas.php?de $\mathrm{s}=3$.

Department of Geology University of Chile. (1998). Manual of Minerology - Fundamentals of Crystallography and Mineralogy. Chile: University of Chile.
Godet Michel. (2007). Strategic Foresight: problems and methods. Paris: Research Laboratory in Strategic Foresight and Organization of the CNAM.

Inei. (2007). Directory of populated centers and dispersed population. Junin: Inei.

Ivan Martinez. (2013). Phosphate deposits: origin, locations, applications of phosphate derivatives and design of a treatment plant. Spain: University of Cantabria.

Mallma Perez I. (2020). Strategic and prospective planning in mining. Huancayo: Valle Azul.

Mantaro Peru SAC (2013). Declaración de impacto ambiental proyecto mantaro. lima: GEA DES Ingenieros SAC.

Observatorio Latinoamericano de Conflictos Ambientales. (2013). El impacto de la minería canadiense en America Latina y la respinsabilidad de Canadá. Misereor. 